\title{
Performances de relações familiares: as charges e seu avesso fotográfico nas representações matrimoniais sul-rio-grandenses (1929-1930)
}

Cláudio de Sá Machado Júnior*

Resumo: $\mathrm{O}$ artigo analisa as performances das relações familiares representadas sob os signos visuais de charges - coluna Bom humor - e confrontadas com as fotografias presentes nas cinquenta primeiras edições do periódico sul-rio-grandense Revista do Globo, tendo como recorte temporal específico os anos de 1929 a 1930. Considera-se a necessidade de uma análise que leve em conta não somente o cruzamento de informações entre o visual e o textual, mas que também leve em conta os diferentes estatutos da imagem, que podem sugerir narrativas diferenciadas de acordo com os parâmetros exclusivos de sua forma comunicativa. Dessa forma, contribui-se para uma análise mais refinada da cultura e da sociedade no passado, estando estes entre os principais objetivos da pesquisa histórica.

Palavras-chave: História. História visual. Humor. Fotografias. Revista do Globo.

\section{Introdução}

A Revista do Globo foi um periódico que esteve em circulação entre os anos de 1929 e 1967. Com sede na cidade de Porto Alegre, pode ser considerada uma das mais importantes publicações da

\footnotetext{
* Professor Adjunto do Departamento de Teoria e Fundamentos da Educação (DTFE) e do Programa de Pós-Graduação em Educação (PPGE), linha de pesquisa História e Historiografia da Educação, na Universidade Federal do Paraná (UFPR). Financiamento: CAPES. Doutor em História pela Universidade do Vale do Rio dos Sinos (UNISINOS). E-mail: claudiojunior@ufpr.br.
} 
imprensa sul-rio-grandense de variedades no século XX. Seu conteúdo caracterizou-se pela diversidade de temas, gêneros textuais e suportes visuais que buscavam a atenção e o interesse de um amplo público consumidor. Nos primeiros anos de sua existência, a revista trouxe no espaço de uma página inteira a coluna intitulada Bom bumor, dedicada às charges que faziam sátira a acontecimentos da vida cotidiana. Essas imagens revelavam, na maioria das vezes, conflitos pertencentes às esferas íntimas concernentes às relações sociais. Considerado como um "instrumento de educação e de difusão de cultura” (REVISTA DO GLOBO, 28 jan. 1939, p. 1), como seus próprios editores a reconheciam, o periódico assumia frente a seus leitores um papel pedagógico de informação e orientação a partir da diversidade de seus conteúdos publicados.

Comprovadamente, as revistas caracterizam-se como importantes suportes materiais para o estudo de parte da cultura visual produzida por nossa sociedade. No caso da História, a cultura visual serve como vestígio representativo que leva ao conhecimento sobre o fragmento de uma determinada época. Nas páginas de uma revista, é possível encontrarmos uma ampla diversidade de elementos de comunicação cujas naturezas - suas essências - foram elaboradas a partir de uma ordenação variada de signos. Em outras palavras, nem sempre os elementos visuais que encontramos dentro dessas páginas seguem um mesmo padrão de concepção na sua forma e, por consequência, na sua intenção de comunicação. E é este caráter polissêmico dos periódicos que nos revela seu potencial e sua riqueza para a investigação sobre as manifestações do social.

Apesar da reconhecida influência das tecnologias nas formas de captação de imagens, diagramação de páginas e impressão completa do produto, nem sempre a opção é feita por aquilo que há de mais prático ou de mais moderno em termos de equipamentos gráficos. No caso da comparação entre charges e fotografias, por exemplo, devemos levar em conta seus estatutos dessemelhantes. Pode ser o que mais nos chama a atenção quando se direcionam a um mesmo objeto de representação. Para incitar algumas reflexões sobre esses dois suportes visuais, charges e fotografias, direcionados para um mesmo objeto, a sociedade e suas relações matrimoniais, é que o presente texto aborda alguns aspectos de sua relação 
dentro de um mesmo espaço de publicação. O historiador Roger Chartier (1993, p. 407) ajuda-nos a pensar um pouco sobre a situação das imagens.

A imagem é então considerada um traço das mentalidades coletivas revelando, mediante uma reprodução individualizada, uma maneira comum de representar o mundo natural, social ou celeste. [...] A imagem é, portanto, para o historiador, ao mesmo tempo, transmissoras de mensagens enunciadas claramente, que visam a seduzir e convencer, e tradutora, a despeito de si mesma, de convenções partilhadas que permitem que ela seja compreendida, recebida, decifrável.

Charges e fotografias são produtos da cultura material humana. Foram criados para gerar uma representação visual cujos usos e funções sociais podem acontecer das mais diversas formas possíveis. No contexto brasileiro da primeira metade do século XX, o desenvolvimento da imprensa gráfica no país facilitou a circulação desses artefatos visuais e propiciou a contemplação e o consumo no âmbito de alguns segmentos sociais do passado. Neste caso, há de se considerar a importância das publicações para a ampliação do conhecimento visual, conforme a tiragem e as formas de circulação do periódico, que, por razões econômicas, nem sempre estava ao alcance de todos, ao menos em suas edições mais recentes. Pelo cuidado e pelo valor, as revistas poderiam ser consideradas menos efêmeras do que os jornais, que com mais rapidez tornavam-se materiais descartáveis propícios para enrolar uma dúzia de ovos ou forrar o interior de um sapato novo.

A periodicidade de uma revista geralmente ocorria dentro do período de uma semana, uma quinzena ou mesmo um mês, dependendo da publicação. No caso da Revista do Globo, periódico em questão, era quinzenal. Se por um lado não trazia a velocidade da divulgação de eventos novos, no frescor de seus acontecimentos, possibilitava uma reflexão sobre o mesmo com um distanciamento de alguns dias. As revistas, portanto, informavam de maneira diferente à moda dos jornais, sem a pressa costumeira do dia a dia, que foi se tornando algo tão característico e inerente à cultura urbana desde

Anos 90, Porto Alegre, v. 21, n. 40, p. 463-492, dez. 2014 
as primeiras décadas do século XX. Lúcia Santaella (2004, p. 116) menciona o poder das imagens em meio ao ambiente cultural criado na primeira metade do século XX.

Fascinado diante da miríade de estímulos, diante do espetáculo volátil das luzes das imagens, dos cenários e das coisas, nas grandes cidades, o olhar moderno aprendeu a desejar, o corpo enfeitiçado das mercadorias que, sacralizadas pela publicidade, ficam expostas à cobiça por trás dos vidros reluzentes das vitrines. [...] A moda explodiu, em meados do século XX, junto com a explosão consumista da cultura de massas, tão transitória quanto são passageiras as imagens nos jornais, nas capas de revistas, nas telas do cinema [...].

No que tange ao alinhamento político da Revista do Globo, percebe-se, nas edições de sua primeira década, um discurso caracterizado em tom muito elogioso aos principais governantes sul-rio-grandenses, sobretudo Getúlio Vargas, que assumiria um importante papel de projeção na política nacional a partir de 1930 e que antes fora administrador no estado gaúcho. A orientação religiosa presente nas páginas do periódico seguia uma tendência católica, dados os teores textuais e a valorização da iconografia (pictórica e fotográfica) cristã nas suas páginas diagramadas. Estas constatações, entre outras, foram perceptíveis após a realização de um exaustivo trabalho de análise da revista, desenvolvido em pesquisa de tese de doutorado na área de História (MACHADO JÚNIOR, 2011). Pode-se deduzir que as orientações morais adotadas pelos editores do periódico poderiam se fazer presentes em seus conteúdos, fossem eles tanto de natureza textual quanto visual. Isso acontece com o discurso em prol da organização social, em que o reconhecimento da constituição familiar necessariamente passava pela união - civil e religiosa - de pessoas do sexo oposto, cujos papéis sociais estavam bem definidos.

Daremos uma atenção especial à maneira como a Revista do Globo expõe sua pedagogia no que se refere à constituição do matrimônio nas condições anteriormente mencionadas, confrontando signos visuais com estatutos diferenciados: as charges e as fotografias. 
Veremos como ambas retratam a questão da constituição familiar, contribuindo, assim, para a realização de uma análise polissêmica dos meios de comunicação, questionando não somente uma forma de linguagem isoladamente, mas considerando, na medida do possível, a miscelânea dos signos presentes nas edições diagramadas da revista. O recorte escolhido para a presente análise delimita-se entre as publicações feitas do supracitado periódico entre os anos de 1929 e 1930, abrangendo, portanto, seus primeiros cinquenta números.

\section{A coluna Bom humor a comicidade}

A primeira edição que circulou da Revista do Globo trouxe a referida coluna no espaço diagramado de pouco menos de meia página, ocupando especificamente a oitava folha da edição, em sua parte superior. $\mathrm{Na}$ ocasião, dividiu espaço com uma publicidade da fábrica Wallig \& Cia, responsável pela industrialização de fogões, cofres e camas de ferro. Após o primeiro número, passou a ocupar uma posição nobre no periódico, ocupando o espaço de uma página inteira. No entanto, nunca esteve em uma folha de numeração específica, sendo publicada em algumas edições nas páginas iniciais e em outras nas centrais ou mesmo finais. Foi um espaço privilegiado para a presença de charges, mas também reservou lugar para piadas apresentadas sob a forma de pequenos textos, caracterizados, em sua maioria, pelo discurso direto. $\mathrm{O}$ número de charges por página também foi algo que variou bastante, mas, no projeto editorial da revista, percebe-se a preferência pela diagramação em três linhas, sendo que cada uma delas poderia ter, aproximadamente, até três charges. Teríamos, portanto, uma estimativa de até nove charges em cada folha dedicada à coluna Bom humor. Podemos considerar algumas aproximações entre a charge e a caricatura no que diz respeito a suas funções sociais, como destaca Herman Lima.

O fato de ser a caricatura considerada elemento dos mais importantes para o historiador do futuro, pelo seu próprio caráter de espelho disfarçado da realidade contemporânea, 
não precisa mais ser posto em relevo, desde que em todos os tempos, como vimos, se tem recorrido à obra gráfica desses Carlyles e Cantus do lápis, para se apreender o verdadeiro sentido de certos fatos de difícil compreensão para a posteridade. (LIMA, 1963, p. 28).

Palavra de etimologia latina, o bumor geralmente está relacionado às questões da comicidade e do riso. Há de se diferenciar no senso comum o "bom" do "mau" humor, caracterizando assim também a sua ausência no estado de manifestações psicológicas e físicas de determinados indivíduos. Apesar das variações existentes nos estudos contemporâneos sobre as expressões faciais, Vladimir Propp (1992, p. 60) lembra que o homem é o único ser capaz de rir. O cômico aplicado ao social passa, geralmente, pela ridicularização e ou depreciação de indivíduos ou grupos, identificando aspectos que poderiam ser considerados como "fora do comum" do ponto de vista de quem exerce a sátira. O mesmo Propp fala que há na comicidade aspectos que se referem a "desvios da norma", ou seja, que rompem com uma ordem vigente. Se pensarmos na comicidade presente na coluna Bom humor, de acordo com os parâmetros do pensador russo supracitado, verificaremos a presença de algo que, em princípio, está se referindo a uma realidade paralela daquela existente nas relações sociais. Verificaremos mais adiante a consistência ou não desta constatação. Ainda sobre o humor, Henri Bergson (2007, p. 64-65) traz-nos importantes reflexões em obra complexa, que pode perfeitamente ser adaptada ao contexto em questão.

Há estados de alma, dizíamos, que nos comovem ao experimentá-los, alegrias e tristezas com as quais nos solidarizamos, paixões e vícios que suscitam o espanto doloroso, ou o terror, ou a piedade nos que os contemplam, enfim, sentimentos que se estendem de alma em alma por ressonâncias afetivas. Tudo isso diz respeito ao essencial da vida. Tudo isso é sério, até mesmo trágico, por vezes. Só quando outra pessoa deixa de nos comover, só nesse caso pode começar a comédia. E ela começa com o que poderíamos chamar de enrijecimento contra a vida social. [...] Daí o caráter equívoco da comicidade. 
Não pertence toda à arte, nem toda à vida. Por um lado, os personagens da vida real não nos causariam riso se fôssemos capazes de assistir aos seus desempenhos como ao espetáculo que olhamos do alto do camarote; eles só nos são cômicos porque representam a comédia.

Bergson fala sobre a indissociação das relações sociais e o riso, que, segundo o autor, "[...] deve corresponder a certas exigências da vida comum” (2007, p. 14). A compreensão da comicidade presente na coluna Bom humor passou, portanto, pela própria experiência da vida social durante o fim da década de 1920 e início de 1930. Nesse caso, o humor presente nas páginas da Revista do Globo deveria ter uma significação social própria, um reconhecimento por parte do público-leitor do que estava sendo ali representado visualmente e textualmente. Do contrário, a coluna não receberia o referido título para o conjunto de charges que desejava apresentar. A representação visual mencionada não trazia os créditos para a identificação de sua autoria. O nome da Revista do Globo indicada no rodapé da página (geralmente à direita nas páginas pares e à esquerda nas ímpares) incitava a noção de autoria das charges ao próprio periódico. No entanto, sabe-se do significativo trabalho de traduções realizado pela revista, especialmente no que concerne a textos literários, filosóficos e informativos. Não se descarta, assim, a hipótese de que essas charges fossem fruto de um trabalho de tradução de seus editores, o que apenas uma pesquisa comparada de amplo fôlego poderia revelar, sobretudo em periódicos estadunidenses e franceses do mesmo período.

\section{Visibilidade das relações matrimoniais}

Relacionando os estudos apontados por Bergson, as charges publicadas na coluna Bom humor buscavam trazer aspectos similares àqueles que poderiam ser encontrados na experiência do cotidiano e, como sugere a leitura de Propp (1992), também àqueles que fariam certo "desvio das normas" das convenções sociais comumente 
adotadas pela sociedade do período. Percebiam-se as charges como a representação jocosa daquilo que poderia ser identificado com uma experiência social, caracterizando aspectos específicos que provocariam, em princípio, o riso. Dentre os aspectos que foram peculiares da vida social projetada pelo conteúdo da Revista do Globo, nota-se que o casamento, em sua experiência diária, estava entre os principais temas escolhidos para a coluna, também se fazendo presente em outras seções do periódico, como nas fotografias, nos discursos textuais e na publicidade em geral. O casamento, aos moldes de fins da década de 1920 e início de 1930, caracterizava-se invariavelmente pela união entre sexos opostos, reconhecida tanto no civil quanto no religioso, e pela consequente geração de filhos. Cabe verificarmos, em um primeiro momento, como estas relações matrimoniais - que foram representadas pelas charges - apresentaram-se à sociedade leitora da revista.

A primeira característica da charge humorística ressalta a capacidade desta representação visual em engendrar narrativas pessoais aos personagens que nela estão sendo representados. Assim, o texto apresenta-se como algo tão importante quanto a própria imagem (LEITE, 1998), pois sua junção exerce um poder comunicacional diferenciado daquele que desempenha o papel de receptor. Nessas condições, o olhar (BOSI, 2002) caracteriza de uma só vez dupla função: ver e codificar. Se a imagem revela certos meandros que dependem da competência de quem está realizando o papel da recepção (VILCHES, 1997), o texto direciona a interpretação das imagens, por vezes atribuindo características que a visualidade por si só não poderia revelar. O interessante das charges é que elas possibilitam a representação de um mundo que, na maioria das vezes, o fotográfico não permite revelar: a esfera da intimidade. Mesmo que fruto da imaginação - uma ficção criada, a rigor, para o divertimento - há uma necessidade latente do reconhecimento social, que neste caso se esmera nos meandros das experiências da vida cotidiana. 
Figuras 1 e 2
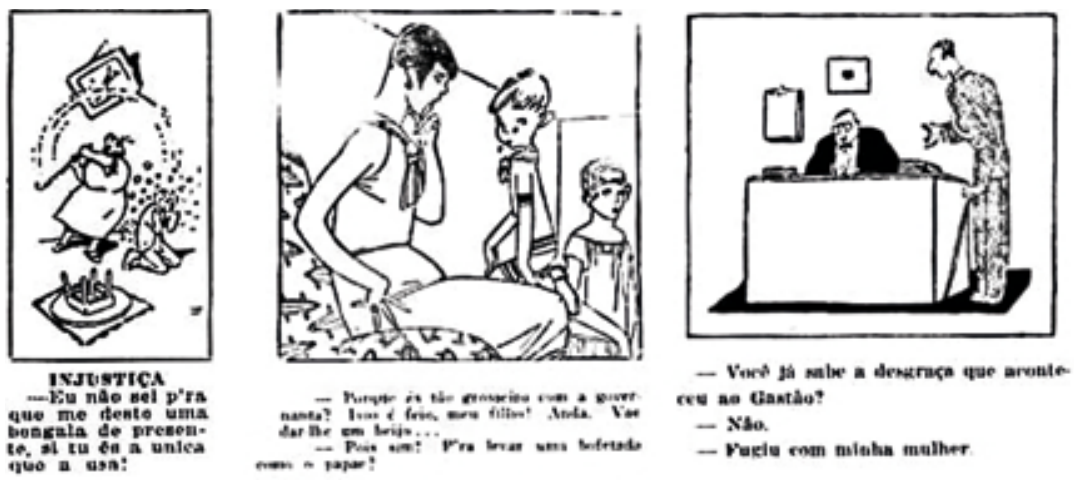

Fonte: REVISTA DO GLOBO. Porto Alegre, n. 3, fev. 1929 (Legenda à esquerda: "Injustiça. / - Não sei pra que me deste uma bengala de presente, se tu és a única que a usa.”); n. 4, fev. 1929 (Legenda ao meio: “- Por que és tão grosseiro com a governanta? Isso é feio, meu filho! Anda. Vai dar-lhe um beijo... / - Pois sim! Pra levar uma bofetada como o papai?” / Legenda à direita: “- Você já sabe a desgraça que aconteceu ao Gastão? / - Não. / - Fugiu com minha mulher”).

As charges da coluna Bom humor, publicadas em preto e branco, favoreciam um olhar constante voltado às relações matrimoniais. No entanto, o foco da comicidade estava mais voltado àquilo que caracterizava a degradação do casamento, que estaria marcado ironicamente pela infidelidade, violência e ausência de amor, do que propriamente às experiências que caracterizariam em outras esferas as relações de união estável. Em duas edições da Revista do Globo, publicadas em fevereiro de 1929, é possível verificar a referida constatação. Em uma delas (figura 1), uma mulher com perfil robusto bate com extrema violência na cabeça de seu esposo com uma bengala, que teria sido, segundo a fala atribuída ao personagem, presente de sua própria mulher. Em um segundo momento (figura 2), a conversa entre mãe e filho revela o assédio do pai à governanta da casa. A empregada, representada por um perfil juvenil, teria dado uma bofetada no rosto de seu chefe, tendo a criança presenciado o acontecimento. Na charge ao lado, na mesma edição, o marido relata a infidelidade da esposa a um amigo, que teria fugido com um homem e agora passaria a "desgraçar" a vida de outro. As experiências cotidianas remetem à ideia de constituição de um teatro social, conforme as palavras de Richard Sennet (1998, p. 53). 
A imagem da sociedade como um teatro não possui um significado único ao passar por tantas mãos e por tanto tempo, mas vem servindo a três propósitos morais constantes: o primeiro foi de introduzir a ilusão e a desilusão como questões fundamentais da vida social, e o segundo foi o de separar a natureza humana da ação social. [...] Em terceiro lugar, e mais importante, as imagens do theatrum mundi são retratos da arte que pessoas praticam na vida cotidiana. É a arte de representar, e as pessoas que a praticam estão desempenhando "papéis" (grifos do autor).

Figuras 3 e 4
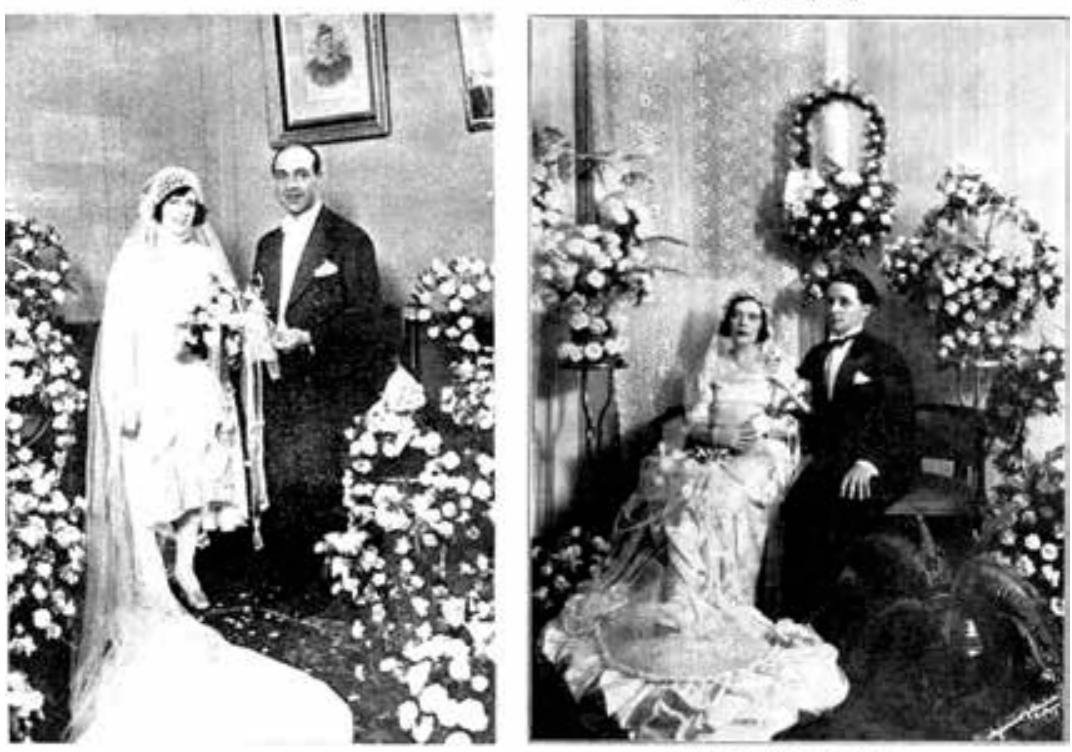

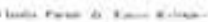

Fonte: REVISTA DO GLOBO. Porto Alegre, n. 11, jun. 1929 (Cabeçalho extraquadro à esquerda: "Enlaces". Legenda extraquadro à esquerda: "Dinah Hecker Porto - Dr. Jorge Moojen da Rocha”); n. 36, jun. 1930 (Cabeçalho à direita: "Enlace”. Legenda da direita: "Cláudia Puente - Dr. Eurico Rodrigues"). 
O eixo central das charges anteriormente mencionadas remete à esfera das experiências decorrentes do casamento, tendo como motivo para a sua criação relações infelizes entre homens e mulheres. Ao contrário, o conteúdo fotográfico presente na Revista do Globo não apresenta em nenhuma circunstância a sociabilidade desenvolvida no âmbito privado que aluda a uma possível tristeza - uma vez que se acredita que não há felicidade em casamentos marcados por relações conturbadas. As fotografias de casamento (figuras 3 e 4), por exemplo, mostravam uma expressão facial de felicidade ou mesmo de serenidade. Aquilo que não estava ao alcance da fotografia poderia ser alcançado somente pela visualidade das charges, pois o ato fotográfico caracterizava-se pela criação de um suporte visual que sofreu em momento específico a negociação entre quem registrava a imagem e os que se deixaram registrar (DUBOIS, 2009). Pode-se afirmar que enquanto a fotografia mostrava aquilo que estava no consenso do fotografado, a charge revelava o que nenhum casal gostaria de ressaltar.

A comparação entre as charges e as fotografias publicadas entre 1929 e 1930 na Revista do Globo traz, dessa forma, o aspecto da identidade dos sujeitos representados como algo a se considerar em sua significativa relevância. Ao contrário das fotografias, as charges trazem sujeitos fictícios que não ferem em nenhum momento a identidade de componentes da sociedade sul-rio-grandense. Por referirem-se a uma "não identidade", permitem-se ingressar na intimidade e revelar situações que, para alguns, poderiam ser um tanto embaraçosas de serem compartilhadas em público. Existe um jogo de identidades que se utiliza da sociedade como parâmetro para criar representações visuais, ao mesmo tempo em que não pode se valer de uma reprodução da sociedade propriamente dita, atribuindo e criando simulacros (CHAUÍ, 2006) a partir de identidades não ficcionais. Maria Lúcia Bastos Kern (2006, p. 28) fala sobre a interferência do artista na criação das imagens, o que pode ser pensado também para o desenhista de charges. 
Apesar de as imagens pictóricas serem produzidas pela mão do artista e preservarem certo fazer artesanal, elas revelam não só o domínio técnico em relação aos materiais empregados e ao controle manual, mas também o cruzamento de conhecimentos, mesclados com a imaginação e a sua visão de mundo.

A violência decorrente dos entendimentos domésticos somente foi considerada como "bom humor" quando exercida da mulher para com o homem, ou seja, quando o personagem feminino foi o agressor e o masculino o agredido. A situação coloca em reflexão a possível inversão de valores que se colocava presente nas experiências da esfera privada entre os casais. Não existe uma charge na qual apareça o homem espancando sua esposa - situação comum para uma época em que não existiam órgãos específicos para a defesa da violência exercida contra as mulheres. Quando aparece, ela é velada ou sutil (figura 5). A comicidade, nesse caso, aparece sob a perspectiva de valores invertidos, em que a mulher é o indivíduo que espanca e o homem, a vítima (figura 6), levando o público leitor, segundo os pressupostos da época, ao riso. Verifica-se que uma pessoa vítima de violência doméstica não gostaria de ver seu drama pessoal exposto em uma coluna de comédia, como caracterizava-se a Bom humor. Assim, temos uma indicação de que a inversão de valores entre homem e mulher certamente parte de um ponto de vista masculino, algo que pode ser verificado na autoria da grande maioria dos textos presentes na revista. 
Figuras 5 e 6
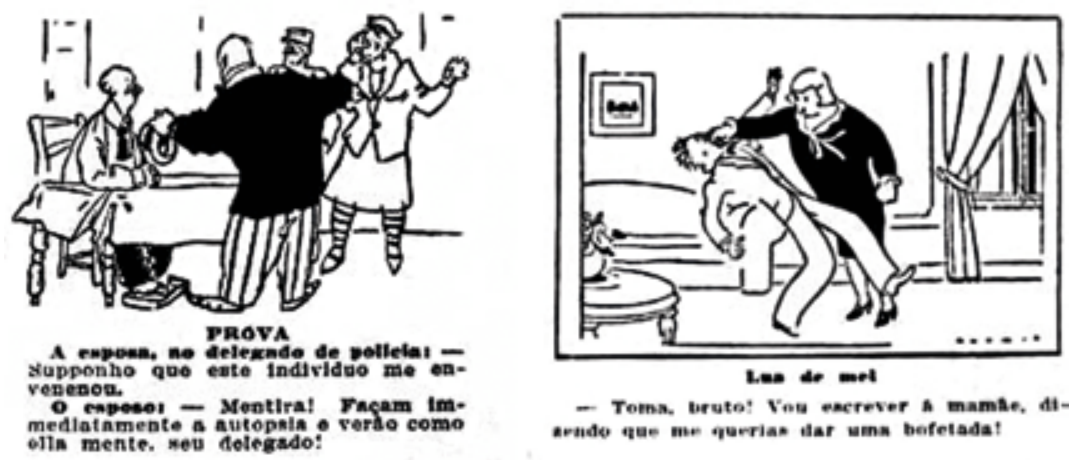

Fonte: REVISTA DO GLOBO. Porto Alegre, n. 22, nov. 1929 (Legenda à esquerda: "Prova. / A esposa no delegado de polícia: - Suponho que este indivíduo me envenenou. / O esposo: - Mentira! Façam imediatamente a autópsia e verão como ela mente, seu delegado!”); n. 12, jun. 1929 (Legenda à direita: “Lua de Mel / Toma, bruto! Vou escrever à mamãe dizendo que me querias dar uma bofetada").

As representações familiares que estiveram nas páginas da Revista do Globo não possuíam uma seção específica, com nomenclatura diferenciada, em comparação com as demais tipologias mencionadas até o momento. Geralmente, estavam difusas ao longo do conteúdo do periódico, ganhando espaço entre outras tipologias visuais ou mesmo entre outros conteúdos comunicativos, como textos, em seus mais diversos gêneros, e publicidade em geral. Outras formas de relacionamento, como mencionado anteriormente, não eram temas presentes às pautas da época, ao menos na revista; pois estariam, na maioria dos casos, relacionados à "promiscuidade" e, provavelmente, representariam um perigo para a constituição tradicional da família nuclear: pai, mãe e filhos. A representação das famílias na publicidade seguia esse parâmetro, como a das canetas automáticas e lapiseiras Wahl Eversharp, veiculada na edição 47, de dezembro de 1930 (figura 7), que reunia, sob o formato de um desenho colorido, uma família ao redor de uma árvore de natal, constituída por dois adultos (homem e mulher) e três crianças (dois meninos e uma menina). 


\section{Figuras 7 e 8}
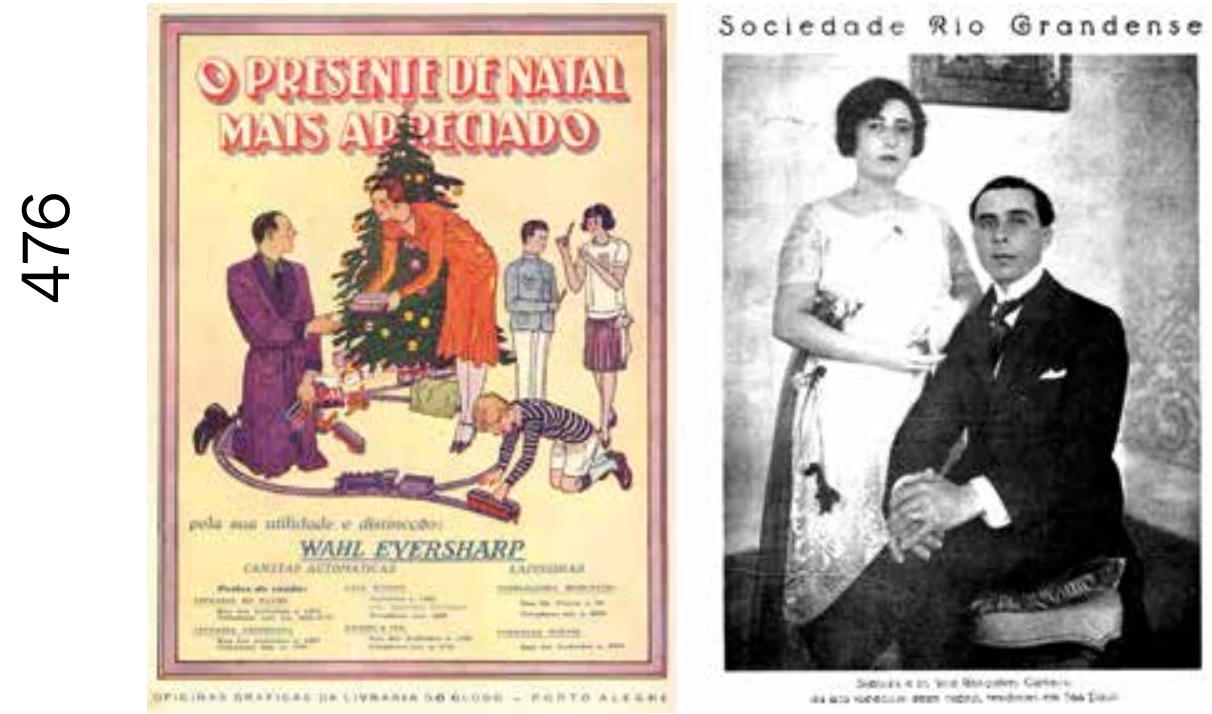

Fonte: REVISTA DO GLOBO. Porto Alegre, n. 47, dez. 1930 (Texto: “O presente de Natal mais apreciado pela sua utilidade e distinção: Wahl Eversharp. Canetas automáticas / Lapiseiras. Postos de vendas: Livraria do Globo, Rua dos Andradas, 1416, Telephone aut. ns. 4232 e 4779 - livraria Americana, Rua dos Andradas, 1297, Telephone aut. n. 4790 - Casa Masson, Andradas, 1465 (esq. Marechal Floriano), Telephone aut. 4255 - Krahe \& Cia, Rua dos Andradas, 1521, Telephone aut. 4720 - Typographia Mercantil, Rua Dr. Flores, 76, Telephone aut. 4308 - Foernges Irmãos, Rua dos Andradas, 1594”. Rodapé: “Oficinas gráficas da Livraria do Globo - Porto Alegre"); n. 9, maio 1929 (Cabeçalho: "Sociedade rio-grandense". Legenda: "Senhora e Sr. José Gonçalves Carneiro, da alta sociedade desta capital, residentes em São Paulo").

A identificação do casal ou da família, no caso da fotografia, está relacionada à associação estabelecida entre a imagem e a legenda, apresentando os componentes do conteúdo visual com signos verbais, tais como os termos "família" ou "grupo familiar". No caso da ausência de um termo propriamente dito, o mais comum seria buscar a constituição por meio do laço consanguíneo de seus componentes: "pai", "mãe", "filho" e "filha". Nestes observa-se o 
uso do sufixo diminutivo que, especificamente no caso dos filhos, também ocorre na forma plural. São raras as imagens, entre charges e fotografias, em que o marido não está presente, sendo representados visualmente apenas a mãe e os filhos (caso tenha mais de um descendente). Quase sempre a menção à figura do esposo está no conteúdo da legenda. É preciso destacar que em algumas fotografias não consta na legenda a identificação de todos os indivíduos presentes no enquadramento fotográfico, com destaque apenas para o nome do homem complementado por "e sua excelentíssima família". Enfatiza a ideia de uma relação matrimonial que tinha na figura masculina a referência familiar, mesmo que a mulher estivesse também presente na imagem (figura 8).

Se analisados isoladamente, charges e fotografias geram uma ideia controversa da sociedade. As diferenças convergem para um mesmo espaço diagramado, caracterizado pelas folhas da Revista do Globo, mas a sua historicidade aponta, desde a sua criação, para diferenças significativas que autorizam usos sociais variados. $\mathrm{O}$ próprio processo de criação da fotografia exige um conhecimento técnico outro em relação àquele da criação em desenho. A compreensão dos meandros sociais e o conjunto de representações criadas pela própria sociedade - tais como as circunstâncias das relações familiares decorrentes do matrimônio - caracterizam-se como vestígios importantes para um conhecimento maior sobre a cultura. O historiador Ulpiano Toledo Bezerra de Meneses (2005, p. 35) menciona a importância de se buscar os signos visuais elaborados pela sociedade para que dela se faça entendimento mais aprimorado de suas formas de representação.

É preciso procurar identificar os sistemas de comunicação visual, os ambientes visuais das sociedades ou cortes mais amplos em estudo. Assim também as instituições visuais ou suportes institucionais dos sistemas visuais (por exemplo, escola, empresa, administração pública, o museu, o cinema, a comunicação de massa, etc.), as condições técnicas, sociais e culturais de produção, circulação, consumo e ação dos recursos e produtos visuais. 
Dessa forma, a Revista do Globo serviu como suporte para difusão de ideias que se criaram a partir de representações visíveis concretas - a charge e a fotografia - demonstrando a intenção de visibilizar formas de como determinados sujeitos interpretavam a sociedade em que viviam e como eles próprios faziam representar a si. Nessas circunstâncias, um jogo complexo de relações sociais autoriza e desautoriza as formas como cada imagem poderá tratar as representações sociais. As delimitações não ocorrem somente através da caracterização técnica, mas também através de contratos sociais que determinam o que pode e o que não pode ser representado. E o que Ulpiano de Meneses determina como o visível, reconhecendo que em uma mesma circunstância poderiam existir múltiplas outras possibilidades que se tornaram omissas ao olhar das gerações de determinada época e, posteriormente, de gerações futuras. O visível estaria mais ligado às esferas de poder que se manifestam na sociedade de diversas maneiras. No caso das charges e fotografias presentes nas páginas da Revista do Globo, aponta para os sujeitos que foram detentores do meio de comunicação, que controlavam determinadas técnicas e que eram responsáveis pelo controle social como um todo. Há também a ilusão da realidade, cuja efetividade dos não detentores do poder podem se fazer omissas frente a uma história social caracterizada de forma tão profunda que tenha tornado a invisibilidade algo enraizado na cultura.

As experiências das charges conotam a difícil vida dos homens que necessitam "suportar" as mazelas do casamento e de suas esposas. A inversão de valores poderia revelar situações de matrimônios cujos papéis seriam trocados, assumindo a esposa o lugar do marido e vice-versa. A opção talvez não aconteça devido ao fato de que a realidade retratada da forma mais próxima do real não proporcione o riso, função principal da coluna Bom humor. A decepção do homem que acorda de um "pesadelo" em que sua mulher teria caído do avião (figura 9, charge à esquerda) e, ao acordar, defronta-se com a realidade - de que sua esposa continua viva - remete à comicidade da infelicidade alheia. $\mathrm{O}$ desconforto social não acontece pelo motivo de as charges se utilizarem de personagens fictícios, identificáveis com a rotina cotidiana, mas não nomeados como sendo personalidades 
específicas da sociedade sul-rio-grandense. Um grande constrangimento poderia ser causado se a charge fosse substituída por uma fotografia posada, exceto na condição de os fotografados serem atores e não sustentarem nenhuma relação amorosa na vivência real.

Figuras 9 e 10
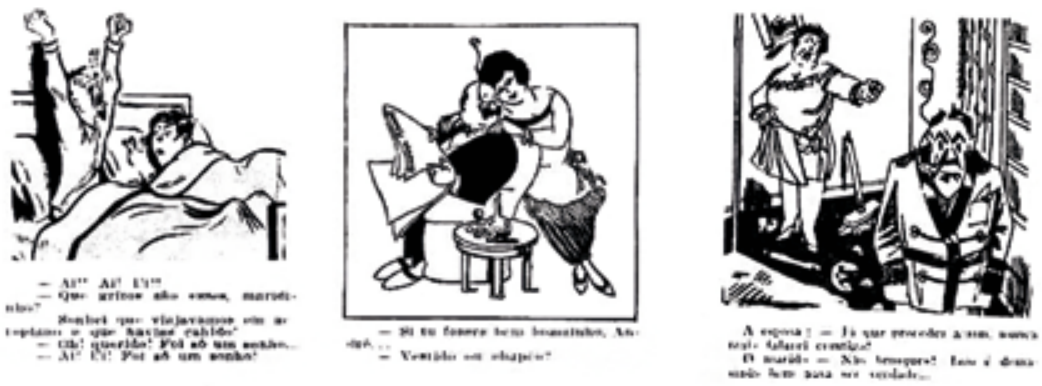

Fonte: REVISTA DO GLOBO. Porto Alegre, n. 5, mar. 1929 (Legenda à esquerda: “- Ai! Ai! Ui! / - Que gritos são esses, maridinho? / - Sonhei que viajávamos em aeroplano e que havias caído. / - Oh, querido! Foi só um sonho... / -Ai! Ui! Foi só um sonho?” / Legenda ao meio: “- Se tu fosses bem bonzinho, André... / - Vestido ou chapéu?”.); n. 15, ago. 1929 (Legenda à direita: “A esposa: - Já que procedeu assim, nunca mais falarei contigo. / - Não brinques! Isso é demasiado bom para ser verdade...”).

As charges possuem as condições de combater o cinismo social, identificável como humor nas páginas da Revista do Globo, mas completamente ausente nas fontes textuais ou fotográficas. A ideia que se fazia presente na convenção social, das décadas de 1920 e 1930, de que o homem trabalha e a mulher cuida da casa e dos filhos se faz presente na charge em que a mulher faz um agrado ao marido em suposta intenção de extorquir dinheiro (figura 9, charge à direita). A narrativa da mulher pedindo dinheiro ao marido reforça a imagem de uma mulher que não é responsável pelo sustento da casa. Ou, se tiver alguma renda oriunda de outra forma de trabalho, não é a principal. O riso mascara a submissão da mulher ao homem, que dele depende financeiramente para atender aos seus anseios pessoais, representados nas charges como algo efêmero e de pouca relevância 
às prioridades financeiras familiares (vestido ou chapéu). Não se cogita a possibilidade de o homem não ter condições financeiras para sustentar os desejos da mulher, excluindo-se a possibilidade da existência de gigolôs e homens pouco dispostos ao trabalho.

A instabilidade das relações faz-se presente na caracterização visual da charge, que traz o mobiliário doméstico em desordem: quadro torto, além de vassoura e vasos quebrados no chão (figura 10). A ironia que parte do homem à mulher expõe ao ridículo o personagem feminino que esbraveja contra ele, perdendo, aparentemente, o senso normal de sua razão. Novamente se reforça a ideia de que é o homem quem suporta a mulher, e não vice-versa. Interessante ao menos observar que as charges que trazem momentos acirrados de discussões entre homens e mulheres raramente trazem a imagem de crianças. Quando elas aparecem, o desentendimento é velado, como se fosse um consenso de que os menores deveriam ser poupados de tamanha discórdia. A ausência de personagens infantis nas charges que mencionam brigas entre maridos e mulheres encobrem as consequências de um lar sem consenso de união, que poderia dar visibilidade ao sofrimento dos filhos para com a ordem familiar, não sendo, dessa forma, objetivo do "bom humor". Louis Marin (1996, p. 123), em contexto específico, ressalta a importância da ausência de imagens para a construção de determinados sentidos, sendo essa invisibilidade também uma condição.

\begin{abstract}
Mas também podemos pensar que essa ausência da imagem vista, em relação ao texto escrito e lido, resulta da própria natureza do meio visual e suas determinações, em comparação àquelas que regem a substância e a forma gráfica.
\end{abstract}

A fotografia, por sua vez, raramente adentra no ambiente doméstico. Em fins da década de 1920, o ambiente preferido de fotógrafos ainda era o estúdio, algo que foi se modificando com os avanços tecnológicos que propiciaram uma maior mobilidade aos aparelhos fotográficos, que passaram a ganhar também o espaço da rua (figura 11). Nas charges, percebe-se uma preferência para a criação de situações que, quando envolvem homem e mulher, 
ocorram em ambientes fechados, sendo estas quase sempre residências domésticas. As relações conturbadas que se verificam dentro do lar não alcançam, dessa forma, o espaço da rua. Reforça a ideia do espaço público como lugar de performances, onde as pessoas se vestem de etiquetas e assumem determinados papéis que se relacionam à sociedade do espetáculo (DEBORD, 1997). As fotografias negociadas retratam, portanto, um mundo de aparências, em que as pessoas dão a si próprias uma visibilidade no mundo que está fora de sua experiência privada. Nesse processo de construção, os fotógrafos "[...] participam como mediadores culturais privilegiados [...]" (MAUAD, 2008, p. 174) da construção da imagem social, circulando pelos espaços que definem circuitos sociais e fornecendo subsídios materiais para a criação de determinada visualidade no espaço das publicações de variedades, como a Revista do Globo.

\section{Figura 11}

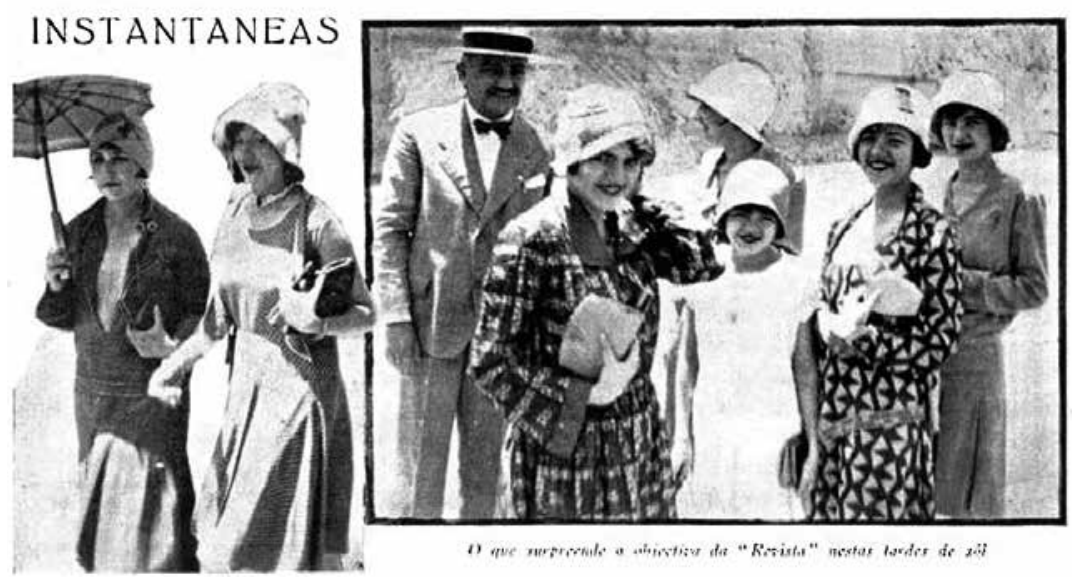

Fonte: REVISTA DO GLOBO. Porto Alegre, n. 2, jan. 1929 (Cabeçalho: "Instantaneas". Legenda: "O que surpreende a objetiva da Revista nestas tardes de sol").

De um lado, o fotógrafo e, de outro, o desenhista, criador de charges. Em ambos, é possível verificar vestígios de ficcionalidade na construção de suas imagens, tendo cada uma sua especificidade 
natural, com características específicas. São representações de um dado real. Para a história, ambas têm significativa importância, mas não podem ser tratadas da mesma forma, pois possuem linguagens diferentes. Estão alocadas naquilo que podemos considerar como cultura visual (apesar da amplitude e não consensualidade sobre o tema, cf. KNAUSS, 2006), sendo apenas pequenas frações de um todo, cada qual com sua peculiaridade sígnica. Uma das principais diferenças entre a charge e a fotografia consiste na busca de seu referente, o que dá ao primeiro maior liberdade de criação, e ao segundo maior estatuto de poder documental. Ambos são documentos visuais, equivalentes enquanto suportes para a história, mas criados de formas completamente diferentes. Sobre a fotografia, em especial, Boris Kossoy (2007, p. 54-55) sugere um aprofundamento desta reflexão.

O dado ficcional é, pois, inerente à imagem, na medida em que a fotografia é um testemunho que se materializa a partir de um processo de criação, isto é, construção. Nessa construção reside a estética de representação. O ficcional se nutre sempre de credibilidade que se tem da fotografia enquanto uma pretensa transcrição neutra, isenta, automática, do real, portanto, enquanto uma evidência documental (herança positivista). A ideia que sempre se propagou da fotografia é a de sua suposta característica de objetividade, do que decorre a certeza de uma "transparência" entre o fato e o registro. A representação ultrapassa o fato e a evidência é exacerbada nessa construção; assim se materializa o índice fotográfico; assim se materializa a prova; o testemunho, a partir do processo de criação. Assim se criam realidades.

O suposto valor indiciário que se apresenta à fotografia também pode se fazer presente nas charges, dadas as suas devidas proporções e considerando a complexidade própria da performance social. Ambos são produtos da representação. No caso das imagens selecionadas para este artigo, elas possuem o mesmo referente: a sociedade e suas relações matrimoniais. No entanto, foram criadas de formas 
diferentes, pois as imagens - fragmentos da cultura visual - têm estatutos próprios. E é justamente a junção de ambos que proporciona a riqueza à História. O que falta para um sobra no outro. A charge, comparando-se à caricatura, tem a possibilidade de deformar o corpo dos seus personagens, reforçando ainda mais o caráter humorístico. Pode colocar narizes arredondados, lembrando palhaços, pessoas gordas, demasiadamente baixas e disformes, caracterizando o riso sem culpa e preconceito algum, uma vez que a representação está consensualmente moldada à ficção. Assim como a fotografia cria seu estatuto de veracidade, dada a similitude da imagem referente, a charge pode correr pelo caminho inverso: ela é representativa de um grupo, mas raramente de uma pessoa específica.

A ausência de identidade da charge, no que tange à sua referência, não ofende uma pessoa em específico, mas pode atingir determinadas classes sociais. No caso da coluna Bom humor, percebe-se um discurso masculino sobre o sexo oposto, com raras exceções. Observa-se uma das charges da edição 42 da Revista do Globo, com dois personagens "bem apessoados" (ou menos caricaturados) mesclando a ideia de casamento e risco à vida (figura 12). Adiantando-se um pouco ao recorte da proposta de análise para este artigo, a revista trouxe uma matéria na edição 193, de outubro de 1936, intitulada: "a mulher mais atraente para o homem moderno reúne estas virtudes - espírito culto, modos senhoris, serenidade, bondade, tolerância e ternura" (REVISTA DO GLOBO, 24 out. 1936, p. 18). Ao que parece, as charges da coluna Bom bumor vão na contracorrente do ideal feminino propagado pelo periódico, em artigo sem referência à autoria. Diz ainda que "[...] nem tudo consiste em ser bela [...]", e que as mulheres "[...] se lastimam, mas sabem resignar-se sem claudicações" (ibid.). O tom humorístico das charges revela uma crítica com relação ao comportamento das mulheres, interpretando em tom satírico aquelas que possivelmente pudessem fugir da convenção social imposta. 
Figuras 12, 13 e 14
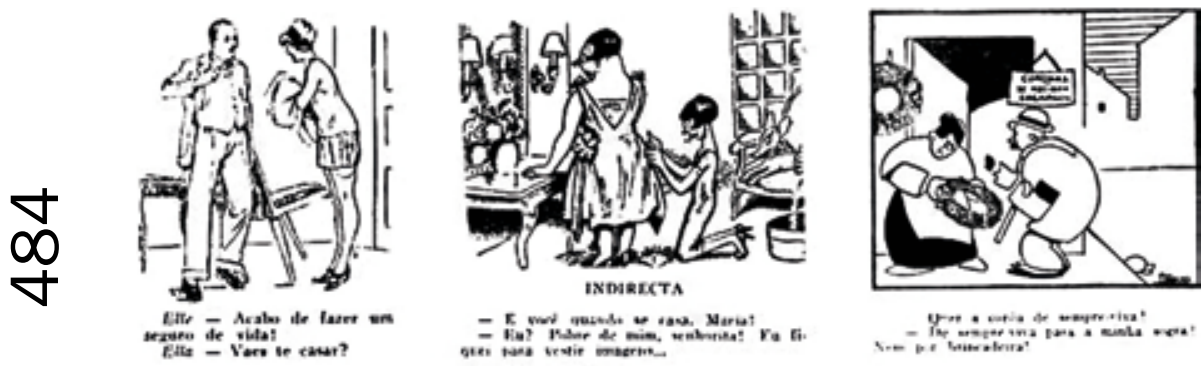

Fonte: REVISTA DO GLOBO. Porto Alegre, n. 42, set. 1930 (Legenda da esquerda: "Ele: - Acabo de fazer um seguro de vida. / Ela: - Vais te casar?"); n. 14, ago. 1929 (Legenda do meio: "Indireta. / - E você quando se casa, Maria? / - Eu? Pobre de mim, senhorita! Eu fiquei para vestir imagens...”); n. 4, fev. 1929 (Legenda: “- Quer uma coroa de sempre viva? / - De sempre viva para a minha sogra? Nem por brincadeira!'”).

Outra constatação interessante aponta para a necessidade de a mulher casar com argumentos não equivalentes às condições do homem. Destino triste seria dado à mulher que não casasse e "ficasse a vestir imagens" (figura 13), ou seja, passaria a se dedicar às atividades da igreja (católica, provavelmente), assumindo para si uma vida de abstenção sexual. Há publicidades na Revista do Globo, especialmente de cosméticos e produtos de higiene, que ressaltam a necessidade de a mulher se embelezar para não "ficar para titia". Por vezes, a mulher sofre um processo de "bruxalização" (LOURO, 2000), recebendo características que se estendem não somente às solteiras, mas também às sogras (figura 14). Neste caso específico, observam-se algumas tipologias fotográficas presentes na Revista do Globo como uma vitrine de moças solteiras em busca do casamento. A identificação da solteirice está conotada por pronomes de tratamento, tais como "senhora" e "senhorinha". No que diz respeito ao homem, parece que o dinheiro bastava, não havendo a necessidade de se preocupar com a beleza ou mesmo com o seu comportamento. Pode-se afirmar que tanto na fotografia quanto nas charges é possível identificar uma intenção do autor, que parte de seu ponto de vista influenciada pelas convenções culturais de sua 
época. Na comparação produtor de imagens e historiador, Peter Burke (2004, p. 24) fala sobre a importância de se reconhecer as intenções dos autores de produtos da cultura.

\footnotetext{
"Estude o historiador antes de começar a estudar os fatos", disse a seus leitores o autor do conhecido livro What is history? [Edward Carr]. Da mesma forma, deve-se aconselhar alguém que planeje utilizar o testemunho de imagens para que inicie estudando os diferentes propósitos dos realizadores dessas imagens. (BURKE, 2004, p. 24).
}

O caos presente nas imagens caricaturais não se faz presente nas imagens fotográficas. Pelo contrário, o respeito do fotógrafo aos fotografados é representado pela ordenação do espaço, pelo cuidado com o enquadramento das pessoas, estabelecendo critérios de claro e escuro que, na revelação em preto e branco, ressaltam uma beleza artística até mesmo imperceptível no local e no momento do registro da imagem. No caso de fotografias que se remetam a cerimônias de casamento, os noivos são colocados em destaque, geralmente ao centro, quase sempre estando a mulher à direita do homem, e ele a sua esquerda (figura 15). Há também todo o cuidado com a disposição das pessoas no espaço da fotografia, tendo-se a cautela para que todos estejam bem representados no produto final do aparelho fotográfico. 
Figura 15
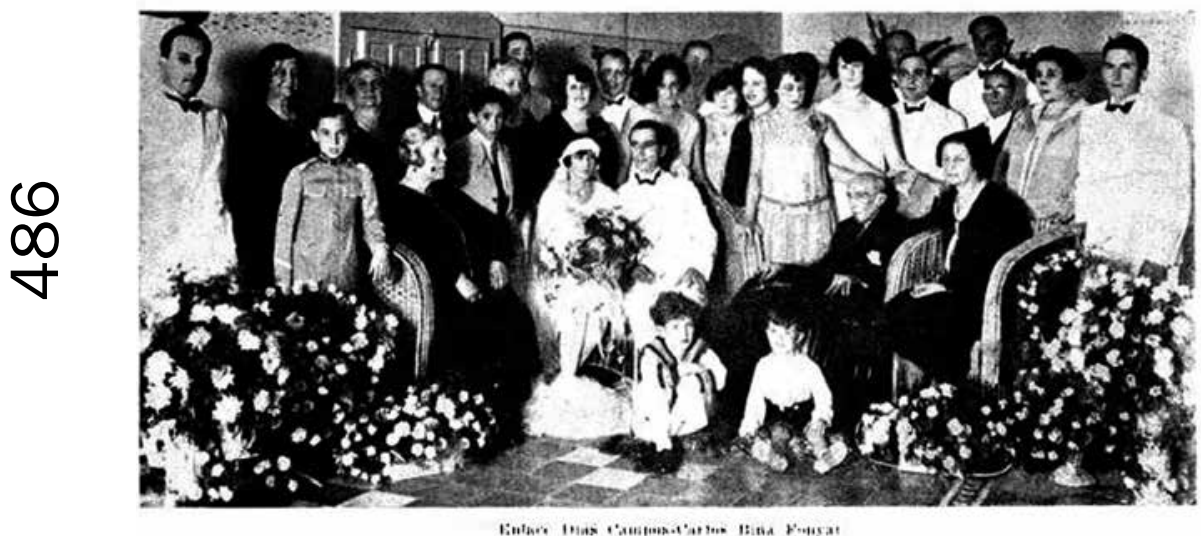

Fonte: REVISTA DO GLOBO. Porto Alegre, n. 2, fev. 1929 (Legenda: "Enlace Dias Campos - Carlos Bina Fonyat”).

A formalidade da fotografia não se faz presente na elaboração de charges. Pelo contrário, os pressupostos do riso sugerem a desordem e a inversão de valores. As flores que se fazem presentes nos atos de cerimônias de casamentos retratados por fotografias aparecem ao chão, resultado de vasos quebrados, nas imagens elaboradas pelas charges. Sobre a fotografia, Miriam Moreira Leite lembra que " [...] nos casos dissidência, fuga ou sedução, o conflito com as famílias torna o casamento 'irretratável' e o retrato só aparece como forma de reconciliação das famílias" (LEITE, 2001, p. 125). Na junção entre as convenções culturais e as conveniências do fotográfico, o estatuto da charge começa onde o acaba o do retrato fotográfico, caracterizando as fronteiras entre o público e o privado, incorporando-se ao segundo a perspectiva do humor, para amenizar as tensões sociais.

O universo masculino que imperou na sociedade da chamada República Velha Brasileira, ou simplesmente Primeira República, fez-se representar nos conteúdos publicados do periódico sul-rio-grandense Revista do Globo. O casamento, veementemente incentivado em diversos aspectos dos códigos culturais presentes na revista, aparece na charge em sua desconstrução, sugerindo que não só de casamentos felizes se constituía o passado. A submissão da mulher, 
desejada pelo universo masculino, também era manifestada nas charges que invertiam os valores de ambos, pois em determinadas situações o humor poderia ser substituído pela denúncia. Uma mulher agredir um homem tornava-se alvo da comicidade, mas a violência do homem contra a mulher já não era alvo de piadas, possivelmente por se constituir em uma manifestação quase comum do cotidiano matrimonial. Assim como a violência escolar estava socialmente autorizada, nas primeiras décadas do século XX, o mesmo acontecia com a violência doméstica.

A transformação da imagem da mulher, que acontecia de forma pejorativa, raramente ocorria com os homens. O descontrole da razão em crises conjugais esteve quase sempre atribuído às mulheres, e praticamente nunca a seus esposos. E algo que foge a simples dicotomia entre sexos: os indivíduos afrodescendentes são efetivamente descartados do universo matrimonial das charges, revelando algo que acontecia também com a fotografia, que levaria o senso comum da história a preservar a memória de um passado construído por uma sociedade "branca". Quando representados, os personagens afrodescendentes desempenham papel de empregados domésticos, sendo quase sempre a figura feminina a prioritariamente representada nesta esfera. $\mathrm{O}$ mesmo pode-se falar da descendência indígena: o projeto de modernização urbana apagou todo e qualquer vestígio de sua presença e de sua herança cultural nas cidades brasileiras. Conforme as referências feitas a Bergson no início deste artigo, pode-se dizer que a comicidade passa, necessariamente, pelo reconhecimento de acontecimentos característicos da esfera cotidiana. No entanto, cabe ao historiador saber trabalhar também com as situações de invisibilidades que envolvem relações de poder sutis que determinados grupos sociais exercem sobre outros. Temos pela análise das performances das relações familiares algumas formas de se conhecer um pouco mais do passado calcado na representação da imagem, cujas charges e fotografias - presentes na Revista do Globo -, além de todos outros referenciais de linguagem, não devem ser trabalhadas isoladamente, mas consideradas em seu conjunto. 


\section{Horizontes de pensamento}

A ausência de sinestesia na fotografia, no que pode dizer respeito a uma história dos odores, remete a outra esfera de reflexão: a ausência do cômico nos retratos fotográficos. As expressões faciais caracterizaram-se como representativas de prováveis "estados de espírito", e cujo suposto estado de alegria seria mais efetivamente representado pela visibilidade do sorriso, caracterizando toda a complexidade e as armadilhas que envolveram o assunto. No entanto, o fato de existir sorriso no rosto de uma pessoa fotografada não necessariamente remete à ideia do cômico na imagem. Quem ri não é a imagem, mas necessariamente aquele que a observa, se a imagem for provocadora do riso, é claro.

A produção do riso na fotografia não necessariamente remete à incitação do mesmo no seu expectador. Podemos assim dizer que, de maneira geral, as fotografias podem não ter a característica de despertá-lo em quem os observava, ao contrário das charges. Inclusive, de acordo com o seu papel social, essa não era uma função a ser cumprida pela fotografia. Novamente sobre a etiqueta fotográfica, poderia se caracterizar até como uma afronta à etiqueta e ao próprio indivíduo expô-lo ao ridículo, uma condição específica para provocar o deboche alheio.

Há também a verificação sobre a presença/ausência do sorriso entre os retratados. Como verificado por Alexandre Ricardo dos Santos (1997), sua contenção foi gradual e culturalmente aceita pelos segmentos de elite somente ao longo da primeira metade do século $\mathrm{XX}$. No entanto, vale lembrar que o sorriso não está exclusivamente relacionado à alegria, visto que se trata de uma expressão corporal da face - externa, não caracterizando o estado psicológico em que o indivíduo se encontrava. Complexamente, uma mulher pode sorrir estando triste, e demonstrar-se séria estando alegre.

Em charges humorísticas publicadas na Revista do Globo, no ano de 1931, posterior ao período em questão, encontramos posicionamentos representativos de um ponto de vista machista, caracterizados por desenhos que abordavam as conquistas e os avanços dos direitos das mulheres, tanto na esfera da participação política quanto no mundo do trabalho. De forma cômica, a "reforma eleitoral e o voto

Anos 90, Porto Alegre, v. 21, n. 40, p. 463-492, dez. 2014 
feminino" e as "profissões femininas de 1932" expunham a condição secundária das mulheres em áreas sociais dominadas predominantemente pelo universo masculino. Vide que a representação da mulher professora não esteve presente, pois essa condição já se caracterizava em uma realidade à época - e, portanto, para alguns não tinha mais graça. A pedagogia da imagem revela as intenções de quem a produz, assim como os possíveis efeitos de quem a consome, conforme denota Roger Chartier (2002, p. 177-178).

As modalidades de apresentação de si são, certamente, comandadas pelas propriedades sociais do grupo ou pelos recursos próprios de um poder. No entanto, elas não são uma expressão imediata, automática, objetiva, do estatuto de um ou do poder do outro. Sua eficácia depende da percepção e do julgamento de seus destinatários, da adesão ou da distância ante mecanismos de apresentação e de persuasão postos em ação.

Observa-se uma depreciação do feminino - vista dessa forma à luz das condições sociais e culturais da contemporaneidade - feita ao "indivíduo-estereótipo", e não diretamente ao "indivíduo-personalidade". Na ausência da verificação da identidade do sujeito nas charges, como mencionado antes em outras palavras, a crítica cômica unilateral da diferença entre os gêneros manifestou-se de forma mais intensa nas charges do que nas fotografias, em tom elogioso e aproximado das noções estéticas, de beleza e de fragilidade.

Discorrer sobre as polissemias visuais na fotografia e nas charges firmou-se como uma opção entre tantas outras que poderiam ser analisadas pelo presente estudo, conforme foi demonstrado nas possibilidades de abordagem do presente artigo, que ao contrário de se fecharem em um estudo em si, abrem janela para novas possibilidades. Mesmo considerando essa variedade, verificaram-se várias sugestões para aprofundamentos de estudo, especialmente comparativos entre revistas de fora do Brasil. Nada melhor do que trabalhar com a impossibilidade do possível - ou a invisibilidade do visível - nas caracterizações não presentes nos retratos fotográficos, demonstrando que, além do caráter polissêmico, a fotografia também omite identidades e determinadas condições sociais.

Anos 90, Porto Alegre, v. 21, n. 40, p. 463-492, dez. 2014 


\section{PERFORMANCES OF FAMILY RELATIONSHIPS: THE CARTOONS AND THE PHOTOGRAPHIC IN RIO GRANDE DO SUL MARITAL REPRESENTATIONS (1929-1930)}

Abstract: This paper analyzes the performance of family relationships represented in the visual signs of cartoons - Bom bumor column - and confronted with the photographs found in 50 editions of the journal from Rio Grande do Sul called Revista do Globo, focusing specific time of the year 1929 to 1930. It is considered the need for an analysis that considers not only the intersection of information between the visual and textual, but also takes into account the status of the image, which may suggest different narratives according to the unique parameters of their communicative way. It therefore contributes to a more refined analysis of culture and society in the past, and these are among the main goals of historical research. Keywords: History. Visual history. Humor. Photography. Revista do Globo.

\section{Referências}

BERGSON, Henri. O riso: ensaio sobre a significação do cômico. São Paulo: Martins Fontes, 2007.

BOSI, Alfredo. Fenomenologia do olhar. In: NOVAES, Adauto (Org.). O olhar. 7. ed. São Paulo: Companhia das Letras, 2002. p. 65-87.

BURKE, Peter. Testemunha ocular: história e imagem. Bauru: EDUSC, 2004.

CHARTIER, Roger. À beira da falésia: a história entre certezas e inquietude. Porto Alegre: UFRGS, 2002.

. Imagens. In: BURGUIÈRE, André. Dicionário das ciências históricas. Rio de Janeiro: Imago, 1993.

CHAUÍ, Marilena. Simulacro e poder. São Paulo: Perseu Abramo, 2006.

DEBORD, Guy. A sociedade do espetáculo: comentários sobre a sociedade do espetáculo. Rio de Janeiro: Contraponto, 1997.

DUBOIS, Philippe. O ato fotográfico e outros ensaios. 12. ed. Campinas: Papirus, 2009.

KERN, Maria Lúcia Bastos. Imagem manual: pintura e conhecimento. In: FABRIS, Annateresa; KERN, Maria Lúcia Bastos. Imagem e conbecimento. São Paulo: EDUSP, 2006.

KNAUSS, Paulo. O desafio de fazer história com imagens: arte e cultura visual. ArtCultura, Uberlândia, v. 8, n. 12, p. 97-115, 2006. 
KOSSOY, Boris. Os tempos da fotografia: o efêmero e o perpétuo. Cotia: Ateliê Editorial, 2007.

LEITE, Miriam Moreira. Retratos de familia: leitura da fotografia histórica. São Paulo: EDUSP, 2001.

Texto visual e texto verbal. In: FELDMAN-BIANCO, Bela; LEITE,

Miriam Moreira (Org.). Desafios da imagem: fotografia, iconografia e vídeo nas Ciências Sociais. Campinas: Papirus, 1998. p. 37-49.

LIMA, Herman. História da caricatura no Brasil. v. 1. Rio de Janeiro: José Olympio, 1963.

LOURO, Guacira Lopes. Mulheres na sala de aula. In: PRIORE, Mary Del (Org.). História das mulheres no Brasil. 3. ed. São Paulo: Contexto, 2000. p. 443-481.

MACHADO JÚNIOR, Cláudio de Sá. Fotografias da vida social: identidades e visibilidades nas imagens publicadas na Revista do Globo (Rio Grande do Sul, década de 1930). 2011. 290 f. Tese (Doutorado em História) - Programa de Pós-Graduação em História, Universidade do Vale do Rio dos Sinos, São Leopoldo, RS, 2011.

MARIN, Louis. Ler um quadro: Uma carta de Poussin em 1639. In: CHARTIER, Roger (Dir.). Práticas de leitura. São Paulo: Estação Liberdade, 1996.

MAUAD, Ana Maria. Poses e flagrantes: ensaios sobre história e fotografias. Niterói: EdUFF, 2008.

MENESES, Ulpiano Toledo Bezerra de. Rumo a uma "história visual". In: MARTINS, José de Souza; ECKERT, Cornélia; NOVAES, Sylvia Caiuby (Org.). O imaginário e o poético nas Ciências Sociais. Bauru: EDUSC, 2005. p. 33-56.

PROPP, Vladimir. Comicidade e riso. São Paulo: Editora Ática, 1992.

REVISTA DO GLOBO. Porto Alegre, n. 1 a 266, jan. 1929 a dez. 1939. Acervo digitalizado e disponível em DVD-ROM.

SANTAELLA, Lúcia. Corpo e comunicaşão: sintoma de cultura. São Paulo: Paulus, 2004.

SANTOS, Alexandre Ricardo dos. A fotografia e as representações do corpo contido (Porto Alegre 1890-1920). 1997. Dissertação (Mestrado em Artes Visuais) - Programa de Pós-Graduação em Artes Visuais, Universidade Federal do Rio Grande do Sul, Porto Alegre, RS, 1997.

SENNETT, Richard. O declínio do homem público: as tiranias da intimidade. São Paulo: Companhia das Letras, 1998. 
Performances de relações familiares...

VILCHES, Lorenzo. Teoría de la imagen periodística. 3. ed. Barcelona: Paidós Comunicación, 1997.

Recebido em: 24/06/2013

Aprovado em: 12/11/2013

ণ

Anos 90, Porto Alegre, v. 21, n. 40, p. 463-492, dez. 2014 